\title{
Seroprevalence of Helicobacter Pylori Infection among Patients with Gastroduodenal Disorders in Erbil City Pshtewan D Majeed $(\mathrm{PhD})^{1}$ and Karim Jwan Saleh Khoshnaw $(\mathrm{MSc})^{2}$ Abstract
}

Background: More than half of the world's population is influenced by Helicobacter pylori infection. The infection is commonly obtained during childhood but may stay asymptomatic, with long-term clinical consequences such as gastritis, peptic ulcer illness, and stomach cancer.

Objective: To determine the prevalence rate of Helicobacter pylori infection and related variables such as age, gender, residency, blood group, Rhesus factors and previous infection among patients presenting with gastroduodenal disorders in Erbil city.

Patients and Methods: Out of 240 blood samples from patients with gastroduodenal disorders admitted to Rzgary Teaching Hospital in Erbil, Iraq from July to August 2019 were collected and screened for anti-Helicobacter pylori antibodies by rapid immunochromatographic assay, and blood groups of patients were determined by using hemagglutination test. For each study subject, a questionnaire sheet was prepared and used.

Results: The overall prevalence rate of Helicobacter pylori infection among 240 patients with gastroduodenal disorders was $128(53.3 \%)$. A significant relationship between Helicobacter pylori infection and gender (male $43.75 \%$ and female $59.72 \%)$ was recorded $(\mathrm{P}<0.05)$. The highest rate of Helicobacter pylori infection was founded among the age group over 50 years, but there were no significant differences between them $(\mathrm{P}>0.05)$. Prevalence was significantly higher among rural areas $(60.4 \%)$ than the urban areas $(48.6 \%)(\mathrm{P}<0.05)$. There was a significant association between Helicobacter pylori infection and $\mathrm{ABO}$ blood group phenotypes $(\mathrm{P}<0.05)$, but there is no significant association between Helicobacter pylori infection and the type of Rhesus factor $(\mathrm{P}>0.05)$. Prevalence was significantly higher among the previous infection $(78.5 \%)$ than non-previous infection $(23.6 \%)(\mathrm{P}<0.05)$.

Conclusion: We found that in Erbil city, the seropositivity of anti-Helicobacter pylori antibody was high among patients with the gastroduodenal disorder. The high prevalence of Helicobacter pylori was founded in the women, elderly, rural area, O blood group, positive Rhesus factor and patients with the previous infection.

Keywords:Seroprevalence,Helicobacter,pylori,gastroduodenal,disorder,Immunochromatographic assay, Erbil city.

Corresponding Author: jwtear.jwan@gmail.com

Received: $18^{\text {th }}$ August 2019

Accepted: $22^{\text {th }}$ September 2019

DOI:https://doi.org/10.26505/DJM.18014880818

${ }^{1,2}$ Department of Nursing-Erbil Medical Technical Institute- Erbil Polytechnic University-Erbil -Iraq. 


\section{Introduction}

Gastroduodenal infections in humans are correlated with Helicobacter pylori ( $H$. pylori) and Infection with $H$. pylori is highly prevalent globally and nearly half the population of the world is infected with it [20].

It is Gram-negative, helical-shaped, microaerophilic, oxidase, catalase, and urease-positive bacterium which usually colonize the human stomach (Christian et al., 2019). The Production of ammonia by this bacteria and release of biochemicals such as proteases, vacuolating cytotoxin $\mathrm{A}$ and phospholipases contribute significantly to its inflammatory and carcinogenic potential [25].

Infections with $H$. pylori are believed to happen soon in life and the infection involves several medical circumstances including gastritis, gastric cancer, gastric adenocarcinoma, lymphoma and peptic ulcer disease [4]. Patients with $H$. pylori are generally asymptomatic and no particular clinical signs and symptoms were outlined. Common signs and symptoms, however, include nausea, vomiting, abdominal pain, heartburn, diarrhoea, evening starvation and bad breath [22].

Almost $70 \%-90 \%$ of the population harbour $H$. pylori in developing countries, the majority of which is obtained during childhood, while the incidence in developed countries is smaller, varying from $30 \%$ to $40 \%$ [23]. Unclean food and water can distribute it and oral-oral or faecal-oral interaction is the most prevalent path of $H$. pylori infection [22]. It has been found that
Ethnicity, socioeconomic status, urban residents, age, bad hygiene circumstances, overcrowding, bad nutrition, bad water supply, and low mother education play a significant role in the transmission of $H$. pylori [37].

There are several techniques for diagnosing $H$. pylori infection that are invasive and noninvasive. The invasive method includes endoscopy and biopsy [histological examination, Rapid Urease Test], and Polymerase Chain Reaction. Non-invasive methods include the Urea Breath Test, stool antigen testing, and serological tests [22]. One of the serological techniques is an immunochromatographic technique which is commonly used for the diagnosis of $\mathrm{H}$. pylori because of its low cost and easy availability at any laboratory [39].

Epidemiological data on the prevalence of $H$. pylori infection to be very scattered in most developing countries including Iraq. The prevalence of $H$. pylori in the neighboring countries was found to be $49.7 \%$ in Kuwait [5], 69.0\% in Turkey [9], 30.1\% in Oman [16], 53\% in Yemen [19], 25\% in Jordan [3], 71.33\% in Saudi Arabia [7], $61.87 \%$ in Iran [38], $42.1 \%$ in Lebanon (Khalife et al., 2017), and $41 \%$ in The United Arab Emirates [33]. As well as, in other countries the prevalence of $H$. pylori was found to be $56.9 \%$ in Kosovo [46], 64.39\% in Cameroon [34], 81.7\% in Nigeria [28] $47 \%$ in Pakistan [39], 27\% in India [25] and 24.3\% in Uganda [4].

In Iraq the incidence of $H$. pylori infection was 55.8\% in Erbil [28], 54.5\% in Basrah 
city [18], 59.2\% in Baghdad city [13], 51.\% in Hilla city [14], $\% 55.8 \%$ in Tikrit city [15], $51.2 \%$ in Sulaimani city [35], 49.62\% in Kirkuk city [1], $51.11 \%$ in Misan city [6], 61.32 in Mosul city [8], and finally $28 \%$ in Duhok city [45] were observed.

The objective of this study was to evaluate the seroprevalence rate of anti- $H$. pylori antibodies among patients with gastroduodenal disorders and its association with some of the epidemiological variables associated with this infection in Erbil city, Iraq.

\section{Patients and Methods}

\section{Sample collection}

This cross-sectional study was carried out on 240 patients with gastroduodenal disorders (gastroesophageal reflux, gastric inflammation, duodenal inflammation, intestinal dysmotility, nausea and vomiting disorders, epigastric pain, and epigastric burning) 96 males and 144 females ranging in age from 18 to 70 years, hospitalized Rzgary Teaching Hospital over a period of two months, starting from 15 June 2019 to 10 August 2019 in Erbil city.

Blood samples were collected from each patient in sterile disposable screw-cap containers. These were labeled with number, date, and name of each subject. A questionnaire containing demographic, clinical, previous infection and environmental data was obtained from each case. The existence of $H$. pylori was investigated by using an immunochromatographic test.

\section{H. pylori antibody}

Detection For serum samples collect blood in a tube without anticoagulant and allow it to clot. After collection, the blood samples were tested immediately by immunochromatographic assay (Camp Medica Group, Bucharest, Romania, 2018) for the qualitative detection of $\mathrm{IgG}$ antibodies specific to $H$. pylori in human serum and were done according to instructions of the manufacturers.

\section{Test Procedure}

1-Draw the sample into the pipette, then dispense $80-120 \mu \mathrm{L}$ of serum or plasma into the sample well of the cassette.

2-Draw the sample into the pipette, then dispense $50 \mu \mathrm{L}$ of whole blood and add 1 drop of diluent provided into the sample well. Use the dropper bottle provided, not the sample pipette.

3-Wait for 10 minutes and then read results. It is important that the background is clear before the result is read. Do not read results after 20 minutes.

\section{Interpretation of Results}

1-Negative: Only one colored band appears on the control (C) region. No apparent band on the test $(\mathrm{T})$ region.

2-Positive: In addition to a pink colored control (C) band, a distinct pink colored band will appear in the test $(\mathrm{T})$ region, as shown in figure (1).

3-Invalid: A total absence of color in either regions or no colored line appears in the control (C) region is an indication of procedure error and/or test reagent deterioration. 


\section{ABO blood group detection}

The ABO blood group was determined for each patient by the conventional hemagglutination test using the anti- A, anti$\mathrm{B}$, and anti-D sera (Torax Biosciences, United Kingdom, 2019). The ABO blood grouping procedure is based on the principle of agglutination or clumping as the patient's blood is reacted with anti-A, anti-B and anti$\mathrm{Rh}$ antibodies separately.

\section{Statistical analysis}

The data were analyzed using Statistical Package for the Social Sciences (SPSS), version 21.0. The proportion and their frequencies were checked by applying the chi-square (x2) test. P-value $<0.05$ was considered significant.

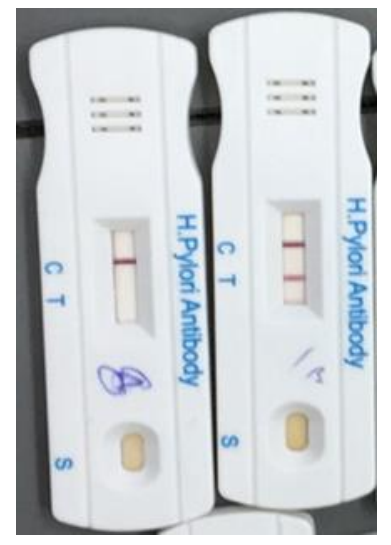

Figure (1): Results of immunochromatographic test: A- Negative Result (left) B- Positive Result (right) Results

A total of 240 patients were included in the present study Figure (2), were found
128(53.3\%) and 112(46.7) seropositive and seronegative cases, respectively.

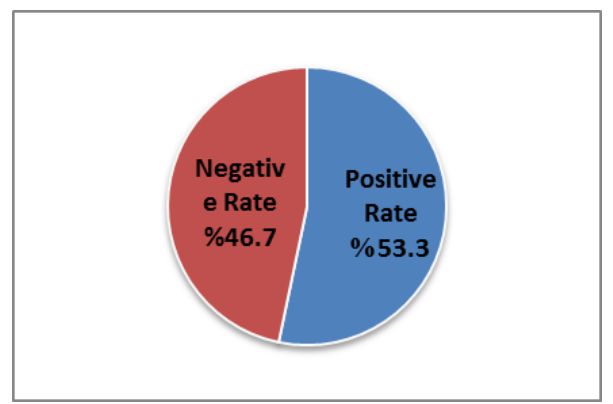

Figure (2): Frequency of anti-H. pylori antibodies in sera of surveyed patients

As shown in Table (1), in 240 blood samples, there were $128(53.3 \%)$ seropositive cases, the high seropositivity in females was $86(59.72 \%)$ and low seropositivity in males was $42(43.75 \%)$. Statistically, a significant difference was observed between males and females $(\mathrm{P}<0.05)$. 
Table (1): Seroprevalence of anti-H. pylori antibodies in relation to gender

\begin{tabular}{|c|c|c||c|}
\hline \multirow{2}{*}{ Genders } & \multicolumn{2}{|c|}{ Test No. (\%) } & \multirow{2}{*}{ Totals } \\
\cline { 2 - 3 } & Positive (\%) & Negative (\%) & \\
\hline \hline Male & $42(43.75)$ & $54(56.25)$ & $96(40 \%)$ \\
\hline \hline Female & $86(59.72)$ & $58(40.28)$ & $144(60 \%)$ \\
\hline \hline Total & $128(53.3)$ & $112(46.7)$ & $240(100 \%)$ \\
\hline \hline \multicolumn{2}{|c|}{ The $p$-value is 0.015106. This result is significant at $p<0.05}$. \\
\hline
\end{tabular}

Seroprevalence of anti- $H$. pylori antibodies according to the age groups were shown in Table (2). The percentage of the seropositivity increased with the age from $(42.85 \%)$ in $<20$ years old to $(60 \%)$ in $>50$ years old. Statistical analysis was shown, that there is no significant difference between age groups and seropositivity of $\mathrm{H}$. pylori infection among patients $(\mathrm{P}>0.05)$.

Table (2): Seroprevalence of anti-H. pylori antibodies in relation to age groups

\begin{tabular}{|c||c|c||c||}
\hline \multirow{2}{*}{$\begin{array}{c}\text { age groups } \\
\text { (years) }\end{array}$} & \multicolumn{2}{|c|}{ Test No. (\%) } & \multirow{2}{*}{ Total } \\
\cline { 2 - 3 } & Positive (\%) & Negative (\%) & \\
\hline \hline$<20$ & $18(42.85)$ & $24(57.15)$ & $42(17.5 \%)$ \\
\hline \hline $21-30$ & $23(44.23)$ & $29(55.77)$ & $52(21.67 \%)$ \\
\hline \hline $31-40$ & $25(50)$ & $25(50)$ & $50(20.83 \%)$ \\
\hline \hline $41-50$ & $30(53.57)$ & $26(46.43)$ & $56(23.33 \%)$ \\
\hline \hline $50>$ & $24(60)$ & $16(40)$ & $40(16.67 \%)$ \\
\hline \hline Total & $128(53.3)$ & $112(46.7)$ & $240(100 \%)$ \\
\hline \hline The $p$-value is 0.487805 . The result is not significant at $p<0.05$. \\
\hline
\end{tabular}

Table (3) shows the prevalence of $H$. pylori seropositivity in relation to residence area. Among patients with the gastroduodenal disorder, the high seropositivity 58(60.4\%) was observed in rural areas, while the low seropositivity $70(48.6 \%)$ was recorded in urban areas. Statistical analysis showed no significant difference between the two groups $(\mathrm{P}>0.05)$.

Table (3): Seroprevalence of anti-H. pylori antibodies in relation to residency

\begin{tabular}{|c|c|c|c|}
\hline \multirow{2}{*}{ Residency } & \multicolumn{2}{|c|}{ Test No. (\%) } & \multirow{2}{*}{ Total } \\
\hline & Positive (\%) & "Negative (\%) & \\
\hline Urban & $70(48.6)$ & $74(51.4)$ & $144(60 \%)$ \\
\hline Rural & $58(60.4)$ & $38(39.6)$ & $96(40 \%)$ \\
\hline Total & $128(53.3)$ & $112(46.7)$ & $240(100 \%)$ \\
\hline
\end{tabular}

As illustrated in the Table (4), the highest seropositivity was founded in the $\mathrm{O}$ blood group $(65 \%)$, followed by A blood group $(54.17 \%)$, B blood group $(45.5 \%)$ and $A B$ blood group (31.82\%). Statistical analysis showed a significant difference between $H$. pylori infection and blood groups $(\mathrm{P}<0.05)$. 
Seroprevalence of Helicobacter Pylori Infection among Patients with Gastroduodenal Disorders in Erbil

Table (4): Seroprevalence of anti-H. pylori antibodies in relation to blood groups

\begin{tabular}{|c||c||c||c|}
\hline \hline Blood group & \multicolumn{2}{|c||}{ Test No. (\%) } & Total \\
\cline { 2 - 3 } & Positive (\%) & Negative (\%) & \\
\hline \hline A & $39(54.17)$ & $33(45.83)$ & $72(30 \%)$ \\
\hline \hline B & $30(45.5)$ & $36(54.5)$ & $66(27.5 \%))$ \\
\hline \hline AB & $7(31.82)$ & $15(68.18)$ & $22(9.17 \%)$ \\
\hline \hline O & $52(65)$ & $28(35)$ & $80(33.33)$ \\
\hline \hline Total & $128(53.3)$ & $112(46.7)$ & $240(100 \%)$ \\
\hline \multicolumn{2}{|c|}{ The $p$-value is 0.017469 . The result is significant at $p<0.05}$. \\
\hline
\end{tabular}

Table (5) shows the rate of $H$. pylori factor negative (50\%) with no significant infection was higher in Rhesus factor differences between $H$. pylori infection and positive $(53.8 \%)$ as compared to Rhesus Rhesus factor $(\mathrm{P}>0.05)$.

Table (5): Seroprevalence of anti-H. pylori antibodies in relation to Rhesus factor

\begin{tabular}{|c||c|c||c|}
\hline \multirow{2}{*}{ Rhesus factor } & \multicolumn{2}{|c|}{ Test No. (\%) } & \multirow{2}{*}{ Total } \\
\cline { 2 - 3 } & Positive (\%) & Negative $(\%)$ & \\
\hline \hline Rhesus ve+ & $114(53.8)$ & $98(46.2)$ & $212(88.33 \%)$ \\
\hline \hline Rhesus ve- & $14(50)$ & $14(50)$ & $28(11.67 \%)$ \\
\hline \hline Total & $128(53.3)$ & $112(46.7)$ & $240(100 \%)$ \\
\hline \hline The $p$-value is 0.706785 . This result is not significant at $p<0.05$. \\
\hline
\end{tabular}

Table (6) shows the prevalence of $H$. pylori seropositivity in relation to the previous infection with $H$. pylori. The high seropositivity $102(78.5 \%)$ was found in patients with the previous infection and the low seropositivity 26(23.6\%) was observed in patients without previous infection. A Significant difference $(\mathrm{P}<0.05)$ was observed between both groups.

Table (6): Seroprevalence of anti-H. pylori antibodies in relation to the previous infection

\begin{tabular}{|c||c|c||c|}
\hline \hline Previous infection & \multicolumn{2}{|c|}{ Test No. (\%) } & \multirow{2}{*}{ Total } \\
\cline { 2 - 3 } & Positive $(\%)$ & Negative $(\%)$ & $130(54.17 \%)$ \\
\hline \hline Yes & $102(78.5)$ & $28(21.5)$ & $110(45.83 \%)$ \\
\hline \hline No & $26(23.6)$ & $84(76.4)$ & $240(100 \%)$ \\
\hline \hline Total & $128(53.3)$ & $112(46.7)$ & 2 \\
\hline \hline \multicolumn{2}{|r|}{ The $p$-value is 0.000 This result is significant at $p<0.05}$. \\
\hline
\end{tabular}

\section{Discussion}

The present research reveals that the overall percentage of $H$. pylori infection was $(53.3 \%)$. This is comparable with other studies in which $H$. pylori infection has been reported such as 55.8\% in Erbil city [28],
$55.8 \%$ in Tikrit city [15], 51.2\% in Sulaimani city [35], and $54.5 \%$ in Basrah city [18], while higher percentage than our findings were observed in Baghdad-Iraq and MosulIraq $(71.3 \%)$ and $(61.32 \%)$, respectively 
[26],[8]. In addition, lower $H$. pylori prevalence rates have been reported by $11.3 \%$ in Erbil-Iraq [11] and 28\% in Duhok-Iraq [45]. These differences could be clarified by the patient's age and health, amount of specimens, population cultural practices, socioeconomic status, ethnicity, testing methods and geographic allocation [7], [44].

The rate of infection with $H$. pylori in female patients $(59.72 \%)$ is significantly higher than in male study participants $(43.75 \%)(\mathrm{P}=0.015)$. It was reported in some studies that the higher rate of $H$. pylori infection was found in females and similarly this difference was usually significant ([21], [39], [40]. In comparison to the results in Baghdad-Iraq, Sulaimani-Iraq and MisanIraq, there is no significant association between the frequency of $H$. pylori and sex Al-Mossawei et al., 2013, [35], [6]. The hormonal variation between the two genders may explain these results or may be related to social reasons that females are more concerned with food preparation than males and spend more time in the kitchen [28], [35].

According to the age groups, a nonsignificant association between the rate of $H$. pylori infection and age groups was noticed $(\mathrm{P}=0.487)$. The percentage of seropositivity increased with the age from $(42.85 \%)$ in less than twenty years old to $(60 \%)$ in more than fifty years old. This result is consistent with other previous research that demonstrated a high incidence of $\mathrm{H}$. pylori infection in more than 50 years ([42], [26], [10], but it differs from other studies conducted in Diyala-Iraq and Mosul-Iraq [27], [8]. The differences between the present results and the results of the other researchs may be attributed to the patient's nutritional status, socioeconomic status, insufficient sanitation, water supply and environment condition [13].

Our study showed that the risk of $H$. pylori infection was higher but not significant $(\mathrm{P}=0.072)$ among participants who live in rural $(60.4 \%)$ than those live in urban areas $(48.6 \%)$. This agree with other studies in Erbil-Iraq [12] and in Misan-Iraq [6] and disagrees with the study conducted in Tanzania [31]. These variations between rural and urban patients could be due to bad water supply, bad sewage disposal, social habits of the population and low education [17], [31].

The rate of $H$. pylori infection was significantly higher for type O blood $(65 \%)$ compared to other blood types $(\mathrm{A}=54.17 \%$, $\mathrm{B}=45.5 \%$, and $\mathrm{AB}=31.82 \%)(\mathrm{P}=0.017)$. This study found that patients with $\mathrm{O}$ blood group were more susceptible to $H$. pylori infection and $\mathrm{AB}$ blood group was less prone to infection. This results was consistent with other studies that condacted in Ethiopia and Nigeria [43], [24], and contrary to some previous studies that performed in Egypt and Erbil-Iraq explaining that the $\mathrm{O}$ blood group did not act as a risk factor for $H$. pylori infection [41], [36]. The higher susceptibility of $\mathrm{O}$ blood group individuals to $H$. pylori infection is most probably due to the higher frequency of secretor status in $\mathrm{O}$ blood group individuals or may be due to the $\mathrm{H}$ antigen represents an important receptor expressed in 
the gastroduodenal mucosal cells to which adheres and enhances colonization of $H$. pylori [30].

This study shows that $53.8 \%$ Rh-positive patients and $50 \%$ Rh-negative patients were positive for $H$. pylori, and therefore showed no strong differences between those that were positive and negative, indicating that the presence of $H$. pylori is not associated with Rhesus factor, which is in agreement with other studies in Baghdad-Iraq and Iran [2], [38].

It was evident that a significant difference was observed between previous infection and non-previous infection in the frequency of $H$. pylori infection $(\mathrm{P}=0.00)$, seropositivity was more prevalent among patients with prior infection $(78.5 \%)$ than non-previous infection ones $(23.6 \%)$. No study was done including the same or different results.

\section{Conclusion}

The prevalence of $H$. pylori seropositivity was high among surveyed population in Erbil city.Higher frequency of anti-H. pylori antibodies was found among rural dwellers, females and patients with $\mathrm{O}$ blood group. The seroprevalence of anti- $H$. pylori antibodies was found to be increased with the age group. Patients with the previous infection had a high rate of $H$. pylori seropositivity. No significant relationship was observed between $H$. pylori infection and Rhesus factors.

\section{References}

[1] Abdul Razaq, A. A., Ali Pambuk, C. I. and Salman, Y. J. 2017. Role of Helicobacter pylori in Gastro-Intestinal Tract Disorders
(GITDs) among Patients in Kirkuk City, Iraq. Biosci. Biotech. Res. Asia. 14(3): 1159-1164. [2]Abdulridha, M. K. 2013. The Relationship between ABO Blood Group Distribution and the incidence of Upper Gastric and Duodenal Ulcer in Iraqi Patients. Iraqi J. Pharm. Sci. 22(1): 97-103.

[3] Abu-sbeih, R. S., Hawari, A. D., Hassawi, D. S. and Al-Daghistani, H. I. 2014. Isolation and detection of Helicobacter pylori from patients suffering from peptic ulcer using biochemical tests and molecular techniques.

A. J. B. B. 10(1): 58-68.

[4]Aitila, P., Mutyaba, M., Okeny, S., Ndawula Kasule, M., Kasule, R., Ssedyabane, F., Okongo, B., Onyuthi Apecu, R., Muwanguzi, E. and Oyet, C. 2019. Prevalence and Risk Factors of Helicobacter pylori Infection among Children Aged 1 to 15 Years at Holy Innocents Children's Hospital, Mbarara, South Western Uganda. J. Trop. Med. Article ID 9303072, 6 pages.

[5]Alazmi, W. M., Siddique, I., Alateeqi, N. and Al-Nakib, B. 2010. Prevalence of Helicobacter pylori infection among new outpatients with dyspepsia in Kuwait. B.M.C. Gastroenterology. 10(14):1-4.

[6]Alhashimi, R. A. H., Alsaad, R. K. A., Alhilfi, H. S. Q. and Althaalibi, S. M. J. 2017. Helicobacter Pylori Infection, Epidemiology, Endoscopic Findings and Associated Socio-Demographic Factors in Uninvestigated Dyspepsia in the People of Misan, Iraq. J. Gastrointest. Disord. Liver Func. 3(2):109-113.

[7]Alhussaini, M. S. 2016. Prevalence of Helicobacter pylori among patients with 
different gastrointestinal disorders in Saudi Arabia. Med. J. Indones. 25(4):214-20.

[8]Ali, A. J. 2018. Prevalence of Helicobacter pylori Infection in Patients Complaining of Epigastric Pain and Dyspepsia, Mosul, Iraq. Sci. J. Med. Res. 2(8):187-188.

[9]Alim, A., Ataş, M., Güneş, T., Özkan, S. and Dündar, N. 2010. Comparison of antigen and antibody detection tests used for diagnosing the Helicobacter pylori infection in symptomatic patients. Basic Clin. Sci. 1(4):61-70.

[10]Al-Jubori, S.S., Al-Kademy, I.M.S., Ali, M.R. and Ali, A.S.M. 2016. Helicobacter pylori among Iraqi patients with suspected gastric ulcer: histopatological study for gastric mucosal biopsies. 10(7): 224-230.

[11]ALmashhadany, D. A. 2018. Application of stool antigen test for monitoring Helicobacter pylori among human in Erbil governorate, Kurdistan region/Iraq. Int. J. Pharm. Sci. 10(11): 49-53.

[12] AL-Mashhadany, D. A., Ismael, L. Q. and Zaki, A. M. 2018. Seroprevalence of Helicobacter Pylori among Human in Erbil Governorate, Kurdistan Region, Iraq. R. J. L. B. P. C. S. 4(2): 268-280.

[13] Al-Mossawei, M. T., Rzooqi, W. H. and Abdulrazzaq, S. 2016. Detection of Helicobacter pylori IgG and IgM Antibodies in Iraqi Dyspeptic Patients. Journal of Biotechnology Research Center. 10(1): 5-9. [14] Al-Sabary, A. H., Abdul Razzaq, M. S. and Wtwt, M. A. 2017. Genotyping of Helicobacter Pylori Isolated From Iraqi
Patient with Upper Gastrointestinal Disease. J. G. P. T. 09(9):121-127.

[15]Alsamarai, A. M., Thegeal, F. and Alobaidi, A. H. A. 2017. Frequency of Biomarkers Positivity in Iraqi Subject with Gastritis. Sci. Int. 5(2):68-83.

[16]Alwahaibi, N. Y., Almahrooqi, B. M. and Alrawahi, S. A. 2013. The Prevalence of Helicobacter Pylori and Gastritis in Oman. J. Dig. Endo. 4(2):29-32.

[17]Al-Windi, A., Hussain, A. H. and Salih, N. 2013. Seroprevalence of anti-Helicobacter pylori antibodies in population of Sulaimani governorate/Kurdistan Region/Iraq. J. Z. S. A. 15 (3):175-185.

[18]Amer, A. N., Hassan, J. G. and AlSaimary, I. E. 2014. Is Helicobacter pylori infections in immunocompromised children a risk factor for cancer? Med. J. Islamic World Acad. Sci. 22(1): 36-41.

[19]A-Ameri, G. A. and Alkadasi, M. N. 2013. The prevalence of Helicobacter pylori and risk factors infection associated in Taiz city, Yemen. Int.J.Curr.Microbiol.App.Sci. 2(8): 226-233.

[20] Aminde, J. A., Dedino, G. A., Ngwasiri, C. A., Ombaku, K. S., Mahop Makon, C. A. and Aminde, L. N. 2019. Helicobacter pylori infection among patients presenting with dyspepsia at a primary care setting in Cameroon: seroprevalence, five-year trend and predictors. B.M.C Infectious Diseases. 19(30):1-9.

[21]Awuku, Y. A., Simpong, D. L., Alhassan, I. K., Tuoyire, D. A., Afaa, T. and Adu, P. 2017. Prevalence of Helicobacter pylori infection among children living in a 
rural setting in Sub-Saharan Africa. B. M. C. Public Health. 17(1): 360-365.

[22]Ayodele, M. B. O., Aaron, U. U, Oluwatayo, G. A. and Wariso, K. T. 2018. Prevalence of Helicobacter pylori infection among suspected peptic ulcer patients in Port Harcourt, South- South, Nigeria. Gazette of Medicine. 6(1): 602-608.

[23]Bello, A. K., Umar, A. B. and Borodo, M. M. 2018. Prevalence and Risk Factors for Helicobacter Pylori Infection in Gastroduodenal Diseases in Kano, Nigeria. Afr. J. Med. Health. Sci. 17(1):41-46.

[24]Christian, S. G., Eze, E. M. and Essor, J. E. 2018. ABO, Rhesus Blood Groups and Hemoglobin Variants Distribution among Individuals with Helicobacter pylori in Igwuruta-Ali, Rivers State. J. A. M. M. R. 28(10): 1-8.

[25]Dhakal, O. P. and Dhakal, M. 2018. Prevalence of Helicobacter pylori infection \& pattern of gastrointestinal involvement in patients undergoing upper gastrointestinal endoscopy in Sikkim. Indian J. Med. Res. 147(5): 517-520.

[26]Gutef, E. H. 2016. Prevalence of Helicobacter pylori infection with peptic ulcer diseases in Iraqi patients. E. J. P. M. R. 3(4): 479-482.

[27]Haggag, Y. N. Samaha, H. A., Nossair, M. A. and Al Aswally, S. A. 2016. Epidemiological Studies on Helicobacter Pylori in Some Animals and Humans. A. J. V. S. 51(2): 275-281.

[28]Hussen, B. M., Qader, S. S., Ahmed, H. F and Ahmed, S. H. 2013. The Prevalence of Helicobacter pylori among University
Students in Iraq. Indian J. Sci. Tech. 6(8):5019-5023.

[29]Hwaid, A. H., Hasan, A. S., Al-Duliami, A. A. and Al-Marjani, M. F. 2013. Seroprevalence of Helicobacter pylori infection and its relation to $\mathrm{Abo} / \mathrm{Rhesus}$ Blood groups in Diyala, Iraq. Inter. J. Cur. Res. 5(12):4268-4271.

[30]Jaff, M. S. 2011. Relation between ABO blood groups and Helicobacter pylori infection in symptomatic patients. Clin. Exp. Gastoenterol. 4:221-226.

[31]Jaka, H., Mushi, M. F., Mirambo, M. M., Wilson, L., Seni, J., Mtebe, M. and Mshana, S.E. 2016. Sero-prevalence and associated factors of Helicobacter pylori infection among adult patients with dyspepsia attending the gastroenterology unit in a tertiary hospital in Mwanza, Tanzania. Afri. Health Sci. 16(3): 684-689.

[32]Khalife, H., Khalife, H., Hassan, K. H., Ghssein, G., El Rashed, Z. and Abdel-Sater, F. 2017. Epidemiology of Helicobacter pylori infection among the healthy population in Lebanon. World J.P.P.S. 6(6):363-372.

[33]Khoder, G., Muhammad, J. S., Mahmoud, I., Soliman, S. S. M. and Burucoa, C. 2019. Prevalence of Helicobacter pylori and Its Associated Factors among Healthy Asymptomatic Residents in the United Arab Emirates. Pathogens. 8(2):1-14.

[34]Kouitcheu Mabeku, L. B., Noundjeu Ngamga, M. L. and Leundji, H. 2018. Potential risk factors and prevalence of Helicobacter pylori infection among adult patients with dyspepsia symptoms in 
Cameroon. B.M.C. Infect. Dis. 18(1): 278299.

[35]Mohammed, M. O., Bayz, H. H. and Maarouf, F. B. 2017. Clinical, Endoscopic and Urea Breath Test among Dyspeptic Patients Referred to Kurdistan Center for Gastroenterology and Hepatology in Sulaimani. Kurd. J. Appl. Res. 2(2): 89-95. [36]Muhemmed, F. R. and Mohammed, K. B. 2016. Association of chronic urticaria with Helicobacter Pylori infection in Erbil: A case-control study. Zanco J. Med. Sci. 20(2):1376-1384.

[37] Omosor, K. I., Omosor, O. H., Adejumo, B. I. G., Ibeh, I. N. and Dimkpa, U. 2018. Comparative Evaluation of Stool Antigen Immunoassay and Blood Antibody Test Methods for the Screening of Helicobacter Pylori Infection in Asymptomatic Adult Population in Delta State, Nigeria. J. Mol. Microbiol. 2(1): 3-9.

[38] Reiisi, S., Shahi, H., Shahi, S. and Damavandi, M. S. 2017. Determination of $\mathrm{ABO} / \mathrm{Rh}$ blood group, sex and age with severity of Helicobacter pylori infection in Iranian gastrointestinal patients. I. J. M. M. 11(2): 81-86.

[39] Rishma, Nawaz, M., Shams, S. Khan, A., Hassan, H., Shah, M. and Gul Afridi, S. 2018. Frequency Distribution and Risk Factors of Helicobacter Pylori Infection in Patients with Gastric Problems in Mardan Pakistan. Biomed. J. Sci. Tech. Res. 3(1): 15.

[40] Samson, E. S., Okeleke, O. J., Richard, A. Y., Gideon, F. T., Olutoyosi, A. L. and Damilola, O. 2018. Screening for
Helicobacter Pylori Infection among Undergraduate Students of a Tertiary Institution using serum Antibody and Stool Antigen Detection Methods. Biomed. J. Sci. Tech. Res. 3(2):1/10.

[41]Shaldoum, F.M. (2015). Helicobacter pylori and Egyptian blood group types. Curr. Sci. Int. 4(04): 714-723.

[42]Tawfeeq, W. F., Ibraheem, M. F. and Kadhem, Z. G. 2013. ClinicoEpidemiological Study of Peptic Ulcer Disease among Children in Three Tertiary Health Care Centres in Baghdad. Iraqi. J. Med. Sci. 11(4): 381-387. [43]Tdege, T., Mengistu, Y., Desta, K. and Asrat, D. (2005). Seroprevalence of Helicobacter pylori Infection in and its Relationship with ABO Blood Groups. Ethiop. J. Health. Dev. 19(1):55-60.

[44]Tsongo, L., Nakavuma, J., Mugasa, C. and Kamalha, E. 2015. Helicobacter pylori among patients with symptoms of gastroduodenal ulcer disease in rural Uganda. Infec. Eco. Epid. 5: 26785.

[45] Yahya, N. B. 2018. Helicobacter pylori seropositivity among children in Duhok city, Iraq. Sci. J. Uni. Zakho. 6(3): 82-84.

[46] Zhubi, B., Baruti-Gafurri, Z., Mekaj, Y., Zhubi, M., Merovci, I., Bunjaku, I., Topciu, V. and Devoli-Disha, E. (2011). Helicobacter pylori infection according to $\mathrm{ABO}$ blood group among blood donors in Kosovo. Journal of Health Sciences. 1(2):83-89. 